\title{
Introducing an Etnosemiotic Approach to Develop Multimedia Material for Supporting the Alphabetization Process for a Mexican Indigenous Language
}

\author{
$\underline{\text { http://dx.doi.org/ijet.v6i3.1660 }}$ \\ Garcia, I. ${ }^{1}$, Pacheco, C. ${ }^{2}$ and Ruiz, J. ${ }^{2}$ \\ ${ }^{1}$ Technical University of Madrid, Spain \\ 2 Technological University of the Mixtec Region, Mexico
}

\begin{abstract}
One of the effects of globalization in countries' education programs is the loss of their native languages. The loss of native languages does not only affect the research work of anthropologists, linguists, and ethnologists; moreover the country's identity and culture. In this context, our research aims to establish some ethnic contexts which influence students' learning and to provide dynamic material to support the learning process in an indigenous language. More specifically, in this paper an etnosemiotic approach is presented to create interactive multimedia material for supporting the alphabetization process in the Zapoteca language in the Mexican Region of Oaxaca. This approach is oriented towards elementary schooling and aims to address some current necessities in indigenous education.
\end{abstract}

Index Terms-Computer based education, ethnography study, semiotic approach, alphabetization process.

\section{INTRODUCTION}

The different languages that are spoken around the world are a part of the cultural patrimony of humanity. Each language expresses a way of seeing the world, it contains the historical memory of people who speak it, and it is a vital part of culture and identity of the indigenous communities. Linguistic researchers calculate along 10,000 years, when the world population was between 5 and 10 million people, 12,000 languages were spoken in the world. Nowadays, world population is over 6 billion people and, according to the National Commission for Indigenous Nations Development in Mexico, "UNESCO recognizes the existence of 6,000 languages in the world, from which a total of $50 \%$ have a high risk of disappearing"

In Mexico a strong reduction in the use of indigenous languages is occurring. In 1824, when Mexican independence was obtained, $93 \%$ of the people used to speak some native language; however, in 2008 this percentage was only a $7 \%$, from which the main loss of speakers were children. Particularly in Mexico, there exist 62 indigenous languages; and 23 are at risk of disappearing.

The phenomenon of linguistic extinction occurs because the use of indigenous languages has been taken out of the public domain, and their communicative functions have been reduced to a communitarian and familiar context, and they do not have the same development opportunities as other languages (English, Spanish, French, among others). In Mexico, the Zapoteca culture is the preColumbian expression of the Zapoteca people who have historically lived in the south of Oaxaca (see Fig. 1). Today, the family of Zapoteca languages is formed from more than 15 languages which are in danger of disappearing.

The 'Zapoteca' name has a Nahuatl origin, which means "the sapodilla three people", and was known in their own language as "binni záa" or "people who came from the clouds" Nevertheless, the new generations of Zapoteca ethnic groups could lose their language if these are not included in the technological advances. In spite of this, indigenous minority populations continue in their struggle to recover from a history of suppression and assimilation by the colonizing forces [26]. That some Mexican indigenous languages have not survived while others are hovering on the brink of extinction, is testament to the effectiveness of such campaigns.

As a strategy to avoid the loss of the Zapoteca language, the Mexican government has separated the elementary schooling into Spanish education and bilingual education (or indigenous education). However, this differentiation has only complicated the problem; because the conditions between urban and indigenous students are not the same. Thus, the government' strategy has worked as a mechanism to eradicate language and culture where indigenous experiences have been pathologised and posi-

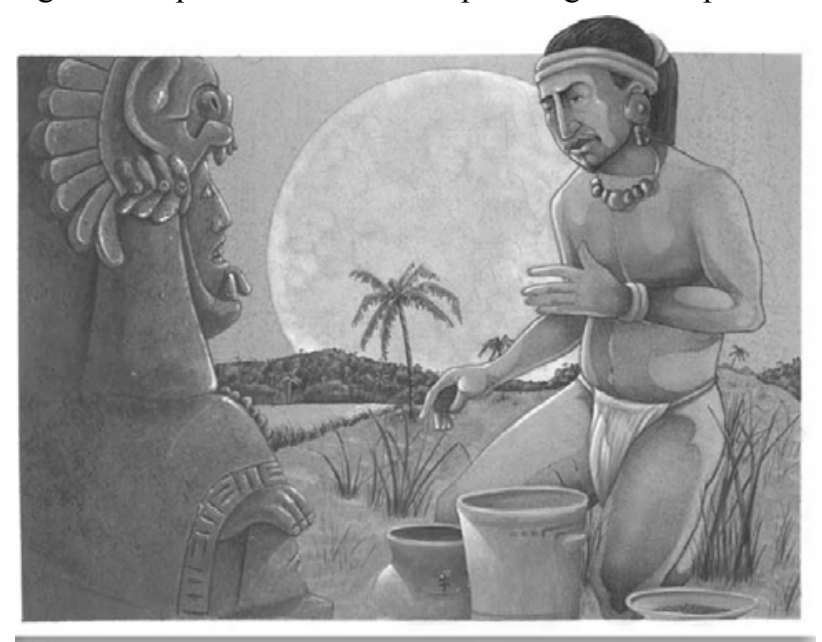

Figure 1. The ancestral Zapoteca culture 
tioned within deficit theorizing. Moreover, the instructional material is not sufficient for indigenous education in the Zapoteca language and teachers are destined to only use blackboards, sheets of paper, regional objects (i.e. jars, dishes, animals, cloths and more), and some local manuals. To reduce the impact of this problem, research such as [16] confirms that the learning process related to languages should be done in the early stages through the interaction of all elements that constitute the environment where children develop their language.

Thus, our research aims to contribute to the creation of didactic material supported by interactive multimedia objects for improving the alphabetization process in early stages. The rest of the paper is organized as follows: Section 2 analyzes the approaches related with native language learning and Section 3 provides detailed information about our proposal. Section 4 resumes the interactive material created as a product of the etnosemiotic approach. Finally, conclusions are summarized in Section 5.

\section{WORK RELATED TO SUPPORT NATIVE LANGUAGES EDUCATION}

According to [1], “language maintenance, in some places referred to as heritage language, and bilingual education, is a classification used to describe those bilingual programmes where the native, home or heritage language of minority language children is giving performance as a medium of instruction and where bilingualism, biculturalism and biliteracy are considered major goals". To resist the effect of language extinction, some countries have developed proposals related to recovering, fortifying, preserving and developing their native languages. Dementi-Leonard and Gilmore documented in [6], for example, a language planning effort funded by an Administration for Native Americans Grant to the Tanana Chiefs Conference, a regional nonprofit tribal organization. Project discussions included options for language planning, training activities, an educational program and material development that would enhance language survival. Three dominant project themes were identified and discussed: (1) critique and resistance, (2) selfdetermination and activism, and (3) collaboration and leadership.

Kasabov et al. focused on language usage and presented a general engineering model of a hybrid system for speech recognition and information retrieval [13]. A case study of building an experimental English - Maori (the native language of New Zealand) talking dictionary; a small dictionary of words and an independent speaker mode for recording.

At the same time, research by [31] highlighted the design of multimedia digital content based on the cognitive instructional design architecture for indigenous content, thought suitable in creating an understanding, and knowledge of the indigenous culture for future workers in Malaysia. Zaman et al. pointed out the necessity to look at indigenous digital multimedia educational content, and the developmental approaches that would meet the needs of indigenous community. As a consequence, research by [14] examined user choice of interface language in a bilanguage digital library or talking dictionary (English and Maori). As a response, the New Zealand government established the "nest of languages" project where the main objective is the preservation of its native language inside education programmes [20].
Norbert Francis performed a study [10] of compositions written in the other language spoken by students, Nahuatl. Subjects were all fluent speakers of both languages, from an indigenous community in Central Mexico. The discussion of the findings examined how the concept of a Common Underlying Proficiency [5] may be applied to a situation of communitywide bilingualism that is characterized by the wide sociolinguistic disparities between the language of schooling and an indigenous language spoken by both students and teachers.

Research by [4] reported on the first results of the DOBES project "Towards a multimedia dictionary of the Marquesan and Tuamotuan languages of French Polynesia”. Within the framework of this project a digital multimedia encyclopedic lexicon of the endangered Marquesan and Tuamotuan languages was developed using a new tool, LEXUS. LEXUS was a Web-based lexicon tool, targeted at linguists involved in language documentation.

Otherwise, Ming. et al. exposes that Mandarin (the native language of China people) learning by integrating Web 2.0 and real-time pronunciation evaluation can become more and more effective and abstractive [19]. The core progress of their system is its powerful interactive learner participation, which drives the creation, organization, communication and sharing of information and experience among learners. Later, the same research presented in [18] the design and implementation of an application system in a pervasive environment for Mandarin eLearning. This approach introduced an e-learning framework including the design of four language skills: listening, speaking, reading and thinking.

In [21] the authors identify the closely related languages amongst the indigenous languages of Sarawak and major languages such as Bahasa Melayu (native languages of Malaysia people) and English. More recently, in [8] the new demands imposed on museums, and the possibilities of achieving them using new Information and Communication Technologies are discussed to propose a platform to collect and interpret artifacts from several indigenous Brazilian cultures.

Thus, it is clear that the conservation of indigenous languages is not a new topic of research. So, the main contribution of the analyzed research attempts to integrate novel approaches to educational content. However, we believe that the preservation of indigenous languages should begin with children's education. Just as we said, indigenous education in the Zapoteca language (and all Mexican indigenous languages) is suffering from the lack of instructional material in learning how to speak, write or read it. During the years, Mexican governments have restricted the indigenous language alphabetization only to indigenous elementary schooling. In some sense, this decision is useful -according to [25, 28, 3 and 9], the early stages are more productive in learning a second language (defining Spanish as first language and Zapoteca language as second). However, if Mexican Spanish education has a lot of trouble with the instructional material; the situation of indigenous education is much too delicate. Thus, our research efforts are focused on three main steps: (1) conduct an ethnographic study to identify common elements in the use of the Zapoteca language, (2) apply the semiotic theory to link ethnical elements to learning objects, and (3) create the multimedia material under an etnosemiotic approach. 


\section{IDENTIFYING COMMON ELEMENTS OF ZAPOTECA LANGUAGE USAGE}

The vision of the educative world, from a qualitative interpretation, currently predominates in the international context. Educational systems have incorporated approaches and methodologies following alternatives tendencies of thinking to obtain a more complete understanding of the environment. Terms as qualitative, ethnography, interpretative, phenomenology, and holistic; have been incorporated with a higher profusion in the curricular speech of the global village. However, in indigenous zones this has not had the same effect.

A major problem in the teaching of indigenous languages, at least in marginalized zones in Mexico (particularly the State of Oaxaca), is identifying and obtaining authentic materials for instructional purposes. The term "authentic materials" is defined as original texts, videos, and recordings of language usage, among other media, that accurately reflect how a language community employs its heritage tongue; but, these materials have not been specifically created for instructional purposes. Thus, a dialogue in a language textbook or manual of usage contrived solely to illustrate a certain usage of a verb or exemplify some grammatical structure is an example of non-authentic materials. Even minority languages (indigenous languages) commonly taught in the State of Oaxaca, which used to have relatively large numbers of speakers, face a dearth of authentic materials. For example, materials created by the Mexican government and employed to teach the Zapoteca language to indigenous elementary school children (one of the largest linguistic minorities in this country), often reflect a willful generalization of language varieties $[11,27,15,30]$, avoiding instead the writing and speech of indigenous communities. Thus, one obstacle to learning indigenous languages is a lack of pedagogical materials and one of the reasons for this is because some indigenous people oppose having their languages written down or recorded. Some people who still speak the Zapoteca language today primarily live in the northern mountain range, Oaxaca and southern parts of Mexico. These speakers are primarily elders, whereas the parents of school-aged children predominantly speak Spanish at work and at home. Today's indigenous schoolchildren are growing up with a very limited competency in the Zapoteca language; they understand little of their ancestral language and speak even less. The educational texts, children's booklets, and language lesson books do not exist. A first example comes from a teacher's Zapoteco lesson book used for individual and, at times, classroom language instruction and has an accompanying illustration image (see Fig. 2).

\begin{tabular}{|c|c|}
\hline \multicolumn{2}{|c|}{ Daily situations } \\
\hline 1. Cha'a tze xhna yochhen za & Mom stewing pan has beans \\
\hline 2. Tzop biz dzelagba to bzinha & Two cats pursue one mouse \\
\hline $\begin{array}{l}\text { 3. Bechh tao dzawba bchhinha yixhe } \\
\text { lhen benerhe }\end{array}$ & $\begin{array}{l}\text { The tiger eats the deer and the } \\
\text { badger }\end{array}$ \\
\hline 4. Bene bionha dzchogue wage lyixe & $\begin{array}{l}\text { That mister cuts firewood in } \\
\text { the field }\end{array}$ \\
\hline 5. Yicha xha'a xhilha nhaken da chich & The lamb wool has white color \\
\hline $\begin{array}{l}\text { 6. Bidao bionha dzape bechh tzebe } \\
\text { chhua yego }\end{array}$ & $\begin{array}{l}\text { The boy takes his bull to } \\
\text { pasture near to the river }\end{array}$ \\
\hline $\begin{array}{l}\text { 7. Lhapa gasj tze bene bionha nhake } \\
\text { xhtanhe }\end{array}$ & $\begin{array}{l}\text { The black hat of that mister is } \\
\text { pretty }\end{array}$ \\
\hline $\begin{array}{l}\text { 8. Lo yel tze xa'nha chhia za'a chhia } \\
\text { (xhen) }\end{array}$ & $\begin{array}{l}\text { The cornfield of my father has } \\
\text { big ears of corn }\end{array}$ \\
\hline
\end{tabular}

Figure 2. An example from a Zapoteco-language lesson
Our study follows the ethnographic research steps, [29, $24,17,2]$, to identify common problems in the Zapoteca language in writing and reading, to understand the way of thinking; the language used by children, and recovering images from children's visual memory (which is associated to different concepts). This process is described as follows:

1. Identification of the studied phenomenon.

2. Identification of informants and participants.

3. Selection of research design.

4. Generation of hypothesis and ethnographic questions.

5. Recollection of information.

6. Triangulation of information.

7. Interpretation of information.

8. Elaboration of conclusions.

9. Organization of final report (or the resultant interactive multimedia material).

Summarizing, the cyclic research model proposed by this ethnographic technique is characterized by its dynamism, flexibility, and dialectic. According to this model, when a researcher decides to study a cultural reality, he participates in this to understand the more significant events from the optic of their own protagonists, with the aim for explaining them and proposing theoretical formulations that represent this reality in a trustworthy way.

\section{A. Zapoteca alphabetization problems}

We select 14 children, 6 students of first grade (two boys and four girls) and 8 students of second grade (four boys and four girls), that it is equivalent to $93 \%$ of the student population. This study begun with a writing exercise in Zapoteca language using 8 sentences (a total of 49 words). The main objective was to identify writing problems related to language usage. Table 1 shows the results reached per child.

The results reveal to us that for a total of 686 words, children incorrectly wrote 379 (a 55\% of words). In some words more orthographic mistakes were detected increas-

TABLE I.

STUDY RESULTS

\begin{tabular}{|c|c|c|c|}
\hline Student & $\begin{array}{c}\text { Evaluated } \\
\text { words }\end{array}$ & $\begin{array}{c}\text { Incorrect } \\
\text { words }\end{array}$ & $\begin{array}{c}\text { Omitted } \\
\text { words }\end{array}$ \\
\hline 1 & 49 & 25 & 6 \\
\hline 2 & 49 & 22 & 4 \\
\hline 3 & 49 & 32 & 4 \\
\hline 4 & 49 & 18 & 2 \\
\hline 5 & 49 & 35 & 6 \\
\hline 6 & 49 & 36 & 4 \\
\hline 7 & 49 & 26 & 2 \\
\hline 8 & 49 & 32 & 3 \\
\hline 9 & 49 & 26 & 2 \\
\hline 10 & 49 & 28 & 2 \\
\hline 11 & 49 & 19 & 2 \\
\hline 12 & 49 & 21 & 2 \\
\hline 13 & 49 & 26 & 2 \\
\hline 14 & 49 & 33 & 2 \\
\hline Total & $\mathbf{6 8 6}$ & $\mathbf{3 7 9}$ & $\mathbf{4 3}$ \\
\hline Average & $\mathbf{4 9}$ & $\mathbf{2 7}$ & $\mathbf{3}$ \\
\hline
\end{tabular}


ing number to $472.6 \%$ of the words were not written. The main findings were classified in the following categories:

- Confusion using incorrectly strong and weak graphy ${ }^{1}$, for example: $\mathrm{x}$ and $\mathrm{xh}, \mathrm{n}$ and $\mathrm{nh}, \mathrm{ch}$ and $\mathrm{chh}$, etc.

- Confusion using broken graphy, for example: a'a, e'e, etc. When a child should use it, he does not do it; or vice versa he uses it when there is no necessity.

- Confusion using cut graphy, for example: a', e', etc. In a similar way, when a child should use it, he does not do it; or vice versa he uses it when there is no necessity.

- Some words are written using an extra word.

- Some words are written incompletely.

- Some words are separately written.

- Confusion using graphy with similar sound, for example: $\mathrm{d}$ and $\mathrm{t}, \mathrm{v}$ and $\mathrm{b}, \mathrm{rh}$ and $\mathrm{lh}$, sh and ll, w and o, etc.

- Some written words are incomprehensible, and

- Use of graphy which do not belong to Zapoteco alphabet.

The work in the Zapoteca community and these preliminary findings enables us to determine the problems related to Zapoteca language learning and usage. Thus, our interactive multimedia material would cover most of the following issues:

- There does not exist a curricular program about the topics and an established order to undertake these contents.

- It is difficult to identify the spellings to be able to write the words, because (and according to teachers and students) some of them have similar sounds.

- The dedicated lapse of time for teaching the Zapoteca language is too short compared with the classes in Spanish.

- The constant use of learned graphy does not exist.

- Text materials in Zapoteca language do not exist. This means that children do not have material to practice reading or the few published materials correspond to another language variant.

- A normal course is more focused on writing and excludes reading.

- The Zapoteca language is only used in the classrooms; outside, in the community, Spanish is the language used.

- The methodology used for teaching the Zapoteca language is good. However, it needs the support of activities and didactic material to improve children's learning process.

- The variant of Zapoteca language spoken by the teachers is not the same one that the community uses. To avoid this problem, the indigenous school uses interpreters to help them clarify the correct pronunciation and write the words in Zapoteco.

\footnotetext{
${ }^{1}$ The English suffix -graphy means either "writing" or a "field of study", and is an anglicization of the French -graphie inherited from the Latin -graphia, which is a transliterated direct borrowing from Greek
}

TABLE II.

ClassROOM EXERCISES

\begin{tabular}{|c|c|}
\hline Category & Words \\
\hline People & $\begin{array}{l}\text { Mister, lady, mother, father, son, boy, girl, } \\
\text { husband, teacher. }\end{array}$ \\
\hline Domestic animals & $\begin{array}{l}\text { Dog, bull, chicken, mule, donkey, cat, pig, } \\
\text { horse, duck, cow, lamb. }\end{array}$ \\
\hline Wild animals & Rabbit, deer, tiger, wild boar, squirrel. \\
\hline Fowl & Bird, eagle. \\
\hline Reptiles & Viper \\
\hline Furniture and tools & Pickaxe, table. \\
\hline Building & House. \\
\hline Flora & $\begin{array}{l}\text { Tree, rose, flower, grove of banana trees, } \\
\text { grazing, firewood, cornfield. }\end{array}$ \\
\hline Satellite & Moon. \\
\hline Times & Yesterday, at night, early morning. \\
\hline Places & $\begin{array}{l}\text { Field, forest, road, house, town, land, river, } \\
\text { tree, backyard, cage, in the water, yard, sky. }\end{array}$ \\
\hline Characteristics & $\begin{array}{l}\text { Pretty, small, big, very big, with color (green, } \\
\text { brown, yellow, white, black, gray), wicked, } \\
\text { large, is male, is woodcutter, run faster, too } \\
\text { high, shining, has wool, is a fighter, is dirty. }\end{array}$ \\
\hline Food & Tortilla, meat, eggs, milk. \\
\hline Fruit & Mango, banana, plum. \\
\hline Seeds & Corn, bean. \\
\hline Toys & Marble. \\
\hline
\end{tabular}

\section{B. Recovering children's language usage}

To understand the way of thinking and to determine the language used by children, two exercises (Spanish writing and Spanish-Zapoteca pamphlets revision) were performed. Table 2 shows some examples of words that children use to compose their orations (showed in categories).

These categories are related to the environment where children interact (communitarian, familiar, and academic contexts). It is important to say that the way that children think is not reduced to these identified categories (24 in total); however, the categories enable to us to understand the language used by children. At the same time, these categories lead us to identify the language that would be used in the educational content of any multimedia material; it means, we can provide a set of linguistic signs more significant for indigenous children.

Multipliers can be especially confusing. Write "Magnetization $(\mathrm{kA} / \mathrm{m})$ " or "Magnetization $\left(10^{3} \mathrm{~A} / \mathrm{m}\right)$." Figure labels should be legible, about 10-point type.

\section{Exploring children's visual memory}

Once that the way of thinking and language usage were identified, we performed an information triangulation through an images production exercise (see Fig. 3). Children drew some words from identified categories and showed them to us. These are their visual images for a defined concept. This analysis is based on the iconic semiotic of Magariños de Morentin [17], particularly in the concept of 'visual memory recovery',

\footnotetext{
${ }^{2}$ The concept of 'visual memory recovery' states that a researcher can identify how an image is interpreted if the interpreter (in our case the child) is converted into an 'image producer' (similar and/or different) and the researcher studies the way that he/she produces them. Thus,
} 
REGULAR PAPER

Introducing an Etnosemiotic Approach to Develop Multimedia Material for Supporting the Alphabetization Process FOR A MEXICAN INDIGENOUS LANGUAGE

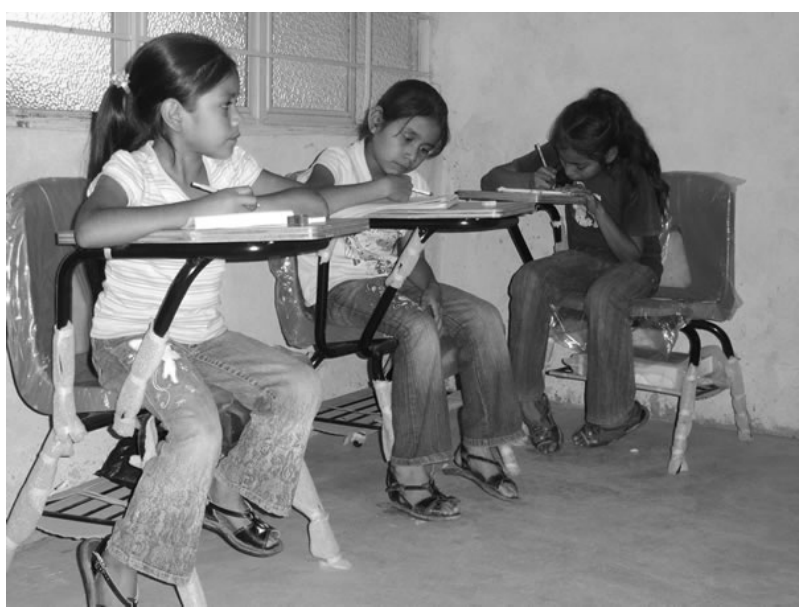

Figure 3. A draw-language exercise

In the study, children from first to fourth grade participated. Four children of first grade ( 3 girls and 1 boy), three children of second grade (1 girl and 2 boys), two of third grade (1 girl and 1 boy) and seven children of fourth grade ( 5 girls and 2 boys).

The idea of different grades participation was used with the objective of identifying a common set of visual signs which represent the defined concepts. The results are showed in Figure 4.

Each identified concept has its own particular description according to the images retained (mnemonic attractor) in the children's memory. For example, almost all children associate with the lady concept - the following visual elements: loose hair, braided hair, short skirt (under the knees), long skirt (above the foot), long sleeve blouse, short sleeve blouse, and huaraches. It is not common to see a lady dressing in pants in the context studied. Generally, ladies (mothers of the children used in this research) have the characteristics showed in Figure 4 (b).

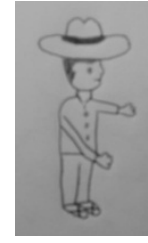

(a) Mister

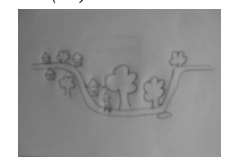

(d) Road

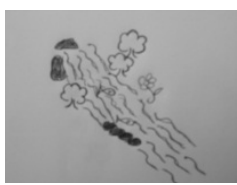

(g) River

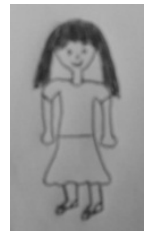

(b) Lady

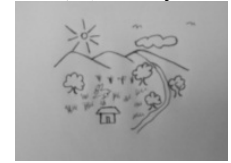

(e) Field

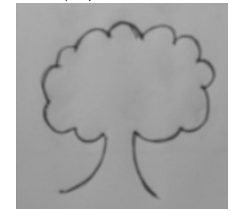

(h) Tree

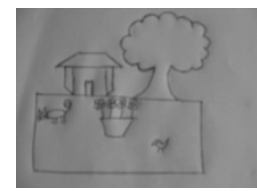

(c) Backyard

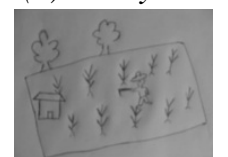

(f) Yard

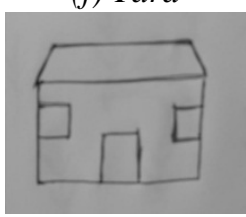

(i) House
Figure 4. A set of common visual signs (different categories)

children interpret the images which interest the researcher in the same way or, at least, in a similar way to these that he is producing and the researcher stimulates.

\section{DEVELOPING INTERACTIVE MULTIMEDIA} MATERIAL FOR SUPPORTING THE ALPHABETIZATION PROCESS IN ZAPOTECA LANGUAGE

Multimedia material for indigenous alphabetization in Mexican Regions is not a common task for linguistic researchers. All advances in this sense are supportive towards publishing books, guidelines, and pamphlets. Similarly to [12], the cognitive instructional design model used for developing the multimedia material took into consideration various entities, such as: knowledge and skills, socialization, environment, learning outcomes, selecting materials, pedagogical strategies, system/children response and evaluation approach.

Firstly, we can not develop educational multimedia material with the technology used in the approaches analyzed in Section 2. The Villa Alta Region (southern mountain range in the State of Oaxaca) is one of the poorest zones in the south of Mexico. Technology (like a PC and Internet connection) is not found in Mexican indigenous schools; however, a TV and a DVD player can be used to improve the alphabetization process.

Figure 5 shows that using the iconic semiotic approach we can design a multimedia environment through the perception of identified visual signs.

Thus, the indigenous teaching and learning coursewares designed using this etnosemiotic approach, would provide flexibility in the classroom and to be able to adapt to selfpaced and self-directed learning. The multimedia material was designed on a cognitive architecture ${ }^{3}$, in order that the learning process is not didactic, but takes into account the use of cognitive theories in the design as can be observed from examples of the print screens.

Figures 6 and 7 show that the evaluation modules of the materials are designed with the aim of making the courseware flexible and individualized enough to ensure that every child is provided with the appropriate learning materials and the opportunity to use them.

Just as we said, the indigenous alphabetization process designed using the etnosemiotic approach, would provide flexibility in the classroom and to be able to adapt to selfpaced and self-directed learning. This approach, com-
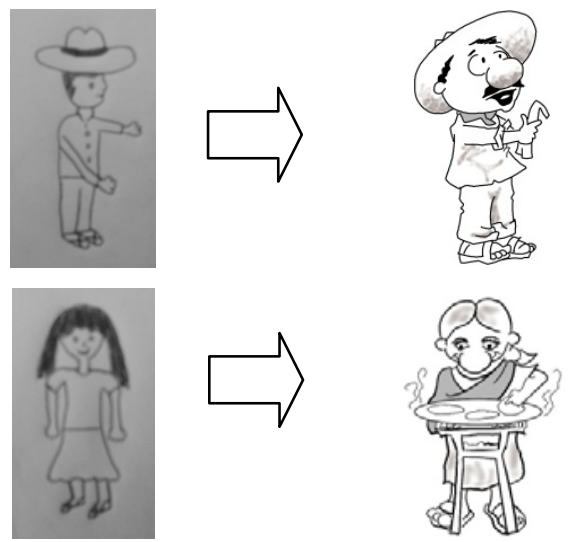

Figure 5. Iconic semiotic in multimedia elements

\footnotetext{
${ }^{3}$ Piaget $[22,23]$ and Bruner were the early cognitive propagators of cognitive theories like the preferred modality theory and the cognitive flexibility theory.
} 
REGULAR PAPER

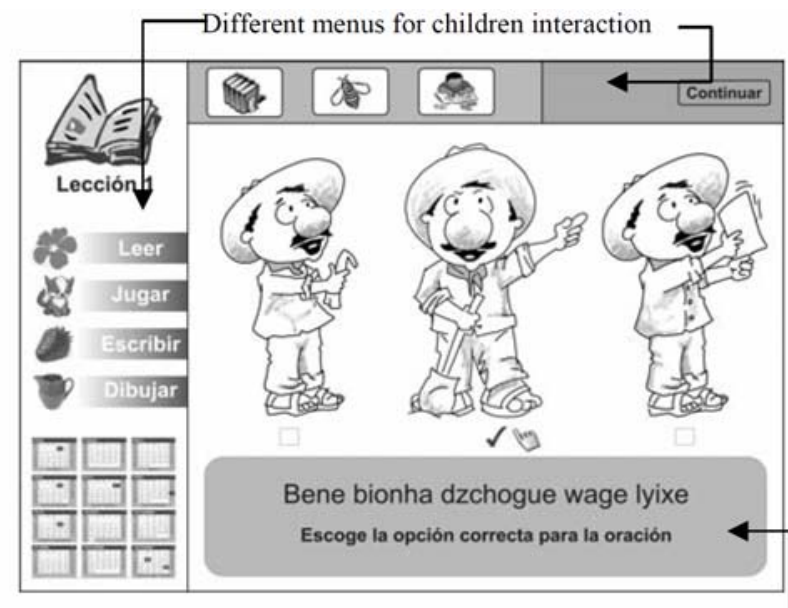

Local graphics showing two sentences: in Spanish an answer of child is requested; and in Zapoteco a sentence is related with only one draw. Problem-solving on elements related to real environment - this is associated to the visual signs information already available in the memory of the indigenous learner.

Figure 6. Use of multimedia elements to interact within learning process

bined with the cognitive theory, will enable children to progress at a faster pace than the average learner and less able children to receive more time and attention at home through a DVD player.

\section{CONCLUSIONS}

Nowadays, the indigenous languages of the world face serious problems of extinction, and the resources (economic, infrastructure, skilled professors, educative materials, methodologies of work, mass media, etc.) are not sufficient to confront this phenomenon. Because the problem is not only of linguistic competition, it is necessary to contribute from diverse knowledge areas. Thus, our research project contributes to the production of didactic material, incorporating the benefits that TI provides to support the alphabetization process in the Zapoteca language, and supporting its development.

Educational contents should evaluate, respect, reuse and study the communitarian experiences to avoid the degradation of its language and culture. The exclusion of indigenous language on curricular programs within the traditional Mexican educative system, has contributed to this degradation, because students are forced to leave their language and culture to have access to education.

The etnosemiotic approach has been fundamental in this research project. Ethnography through the observation, interviews, revision of notebooks, and writing exercises, has allowed to us to explore and explain the current problems of children related to write/read in the Zapoteca language, as well as to understand the way of thinking and language used by children. These issues have simultaneously established the rule about the direction that interactive multimedia material and language should take, in managing the thematic contents. On the other hand, the iconic semiotic of Magariños has been the key to propose iconic elements to children; the image production exercise has allowed the recovery of images from the children's visual memory, which are associated with different concepts. For example, the image that children associate to the 'Mister' concept is related to the 'field' concept, thus interpreting a visual perceptual proposal. Understand the

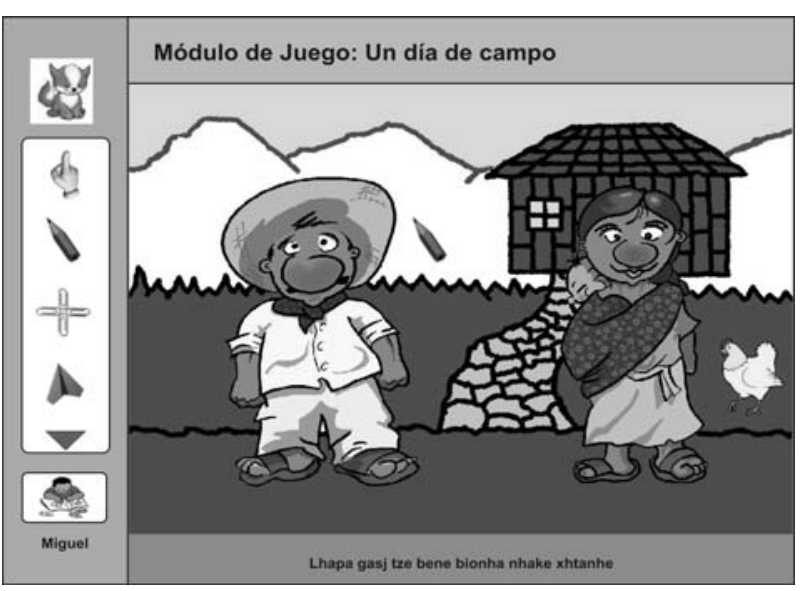

Figure 7. A game modality for learning

language and images that children associate with different concepts, allows us to propose a repertoire of visual signs (linguistic and iconic) that are familiar and significant for these students, that they are able to recognize and to interpret easily, which would facilitate the assimilation of contents, since finally, it is what the students know and speak, the reason why a more significant learning is expected.

\section{ACKNOWLEDGMENT}

This paper is sponsored by the National Council of Science and Technology and the Technological University of the Mixtec Region.

\section{REFERENCES}

[1] Baker, C. and Jones, S. Encyclopedia of bilingualism and bilingual education. Clevedon, UK: Multilingual Matters. 1998.

[2] Buendia Eisman, L., Colas Bravo, M. and Hernandez Pina, F. Metodos de investigacion en Psicopedagogia. Madrid: McGrawHill. 1988. (in Spanish).

[3] Buescher, K. Reading in a Second Language Classroom: A Pedagogical Report on Sociocultural Strategies for Reading Texts in the Elementary French Classroom. University of Massachusetts, 2009.

[4] Cablitz, G., Ringersma, J. and Kemps-Snijders, M. "Visualizing endangered indigenous languages of French Polynesia with LEXUS" Proc. of the 11th International Conference Information Visualization (IV '07), IEEE Computer Society, pp. 409-414, 2007.

[5] Cummins, J. Language, power and pedagogy: Bilingual children in the crossfire. Clevedon: Multilingual Matters. 2000.

[6] Dementi-Leonard, B. and Gilmore, P. "Language Revitalization and Identity in Social Context: A Community-Based Athabascan Language Preservation Project in Western Interior Alaska" Anthropology \& Educational Quarterly, 30(1): 37-55, 2008.

[7] Dominguez, L. Nuevas tendencias de la investigacion social. Mexico: Trillas. 1989. (in Spanish).

[8] Felgar de Toledo, M., Capretz, M. and Allison, D. "Recovering Brazilian Indigenous Cultural Heritage Using New Information and Communication Technologies" Proc. of the 2009 IEEE/WIC/ACM International Joint Conference on Web Intelligence and Intelligent Agent Technology, IEEE Computer Society, pp.199-202, 2009.

[9] Francis, N. "Literacy, second language learning, and the development of metalinguistic awareness: A study of bilingual children's perceptions of focus on form" Linguistics and Education, 13: 373404, 2002. http://dx.doi.org/10.1016/S0898-5898(01)00077-8

[10] Francis, N. "Bilingual children's writing: Self-correction and revision of written narratives in Spanish and Nahuatl" Linguistics and Education, 16: 74-92, 2005. http://dx.doi.org/10.1016/ j.linged.2005.10.003 
REGULAR PAPER

Introducing an Etnosemiotic Approach to Develop Multimedia Material for Supporting the Alphabetization Process FOR A MEXICAN INDIGENOUS LANGUAGE

[11] Gallardo, G. "Presentation at the general report of the Commission Ciudadana de Estudios against the Discrimination titled Discrimination in Mexico: for a new equality culture" Revista Mexicana de Ciencias Politicas y Sociales, 182-183: 261-319, 2001.

[12] Halimah, Z., Norhayati, M., Tengku, S. and Azlina. A. "Indigenous Multimedia Content Development for Next Generation Smart Schools: A Cognitive Instructional Design Approach", Proc. of the Fifth IEEE International Conference on Advanced Learning Technologies (ICALT'05), IEEE Computer Society Press, pp. 487-488, 2005.

[13] Kasabov, N., Sinclair, S., Kilgour, R., Watson, C., Laws, M. and Kassabova, D. "Intelligent human computer interfaces and the case study of building English-to-Maori talking dictionary" Proc. of the 2nd New Zealand Two-Stream International Conference on Artificial Neural Networks and Expert Systems (ANNES '95), IEEE Computer Society, pp. 294-297, 1995.

[14] Keegan, T. and Cunningham, S. "Language preference in a bilanguage digital library" Proc. of the 5th International ACM/IEEE-CS joint Conference on Digital libraries, ACM Publisher, pp. 174-175, 2005.

[15] Llamas, A. "Discriminacion desde la lengua" La Gaceta, 13. Universidad de Guadalajara, 2008. (in Spanish).

[16] Luria, A. and Yudovich, F. Speech and the development of mental processes in the child. Harmondsworth, UK: Penguin Books. 1972.

[17] Magariños de Morentin, J. La semiotica de la imagen visual. Cuadernos 17: 295-320. Universidad Nacional de Jujuy, Argentina. 2001. (in Spanish).

[18] Ming, Y. and Miao, Z. "A Mandarin E-learning System Based on Pervasive Environment" Proc. of the International Conference on Computer Science and Software Engineering, IEEE Computer Society, pp. 206-209, 2008.

[19] Ming, Y., Miao, Z., Ji, X. and Ren, R. "A Mandarin e-Learning System Based on Web 2.0 and Speech Communication" Proc. of the International Conference on Advanced Language Processing and Web Information Technology, IEEE Computer Society, pp. 175-180, 2008.

[20] Ministry of Education. Ka hikitia-managing for success: The Māori Education Strategy 2008-2012. Wellington: Ministry of Education. 2008.

[21] Ng, E., Yeo, a. and Ranaivo-Malancon, B. "Identification of Closely Related Indigenous Languages: An Orthographic Approach" Proc. of the 2009 International Conference on Asian Language Processing, IEEE Computer Society, pp. 230-235, 2009.

[22] Piaget, J. Psychology of Intelligence. Totowa, Littlefield Adams, Totowa, NJ, 1947.
[23] Piaget, J. Piaget's Theory. In P.H. Mussen (Ed) Third edition. John Wiley, New Jersey, 1970.

[24] Preissle-Goetz, J. and LeCompte, M. "Qualitative Research in Social Studies Education" Handbook of Research on Teaching. 6. 291-312 Greenwich Press Inc.1991.

[25] Ratner, N. and Bruner, J. "Games, social exchange and the acquisition of language" Journal of Child Language, 5: 391-401, 1978. http://dx.doi.org/10.1017/S0305000900002063

[26] Rau, C. "Assessment in Indigenous Languages Programmes" Encyclopedia of Language and Education (7): Languages Testing and Assessment. pp. 2450-2461. Springer US, New York. 2008.

[27] Rolstad, K. "Language death in Central Mexico: The decline of Nahuatl and the new bilingual maintenance programs" The Bilingual Review, 26: 3-18, 2001.

[28] Schickedanz, J. More than ABC: The Early Stages of Reading and Writing. National Association for the Education of Young Children. Washington, DC. 1986.

[29] Titone, R. "Bilingual education and the development of metalinguistic abilities: a research project" International Journal of Psycholinguistics, 10(27): 5-14. 1993.

[30] Vargas, P. and Flores, J. "Los indigenas en ciudades de México: el caso de los mazahuas, otomíes, triquis, zapotecos y mayas", Papeles de Poblacion, num. 34, October-December, Centro de Investigacion y Estudios Avanzados de la Poblacion/UAEM, Toluca. 2002. (in Spanish).

[31] Zaman, H., Mukti, N., Sembok, T. and Ahmad, A. "Indigenous Multimedia Content Development for Next Generation Smart Schools: A Cognitive Instructional Design Approach" Proc. of the Fifth IEEE International Conference on Advanced Learning Technologies (ICALT'05), IEEE Computer Society, pp.487-488, 2005.

\section{AUTHORS}

Garcia, I. (igarcia@zipi.fi.upm.es) is with the Languages and Informatics System and Software Engineering Department, Faculty of Computer Science, Technical University of Madrid, Spain.

Pacheco, C. (leninca@mixteco.utm.mx) is with the Postgraduate Department of the Technological University of the Mixtec Region, Mexico, + (953)5320399.

Ruiz, J. (jruiz@mixtli.utm.mx) is with the Technological University of the Mixtec Region, Mexico, + (953) 5320399.

Received May $2^{\text {nd }}, 2011$. Published as resubmitted by the authors August $2^{\text {nd }}, 2011$. 